\title{
Delivery of constant air-oxygen mixtures using a closed circle absorber system
}

The aim of this study was to devise and validate a technique to deliver constant air-oxygen mixtures from a standard anaesthetic machine using only oxygen as the compressed gas source. The common gas outlet was modified to allow measured quantities of ambient air to be insufflated via a three-way attachment into a closed circle absorber system with a doublecircuit collapsible bellows ventilator. During positive pressure ventilation, leakages of between $50-150 \mathrm{ml} \cdot \mathrm{min}^{-1}$ occur from the circuit and nomograms of the minimal air and oxygen flowrates needed to maintain constant oxygen concentrations in the presence of the leaks were then mathematically derived. The accuracy of the nomograms was tested on three different anaesthetic machines using test lung models. There were no differences observed among the mean oxygen concentrations using the three machines. Pooled mean values (SD). of $30.65 \%$ (0.77), $51.07 \%$ (1.04) and $70.4 \%$ (0.73) were obtained for predicted inspired concentrations of 30,50 and $70 \%$ respectively. Next, the technique was studied on 18 patients who underwent isoflurane or propofol anaesthesia (duration 40-210 min) for various surgical procedures. Pooled mean values (SD) obtained were $29.3 \%$ (1.86), $40.95 \%$ (1.65) and $50.06 \%$ (1.41) respectively for predicted oxygen concentrations of 30,40 and $50 \%$ respectively. We conclude that this technique can be used to deliver constant air-oxygen mixtures accurately during inhalational or total intravenous anaesthesia when $\mathrm{N}_{2} \mathrm{O}$ is contraindicated but a source of compressed air is not readily available.

Cette étude vise l'élaboration et la validation d'une technique d'administration continue de mélanges air-oxygène à partir d'un appareil d'anesthésie standard en utilisant de l'oxygène comme la seule source de gaz comprimé. L'orifice de sortie des gaz

\section{Key words}

ANAESTHETIC TECHNIQUES: closed circle.

From the Department of Anaesthesia, Tan Tock Seng Hospital, Moulmein Road, Singapore 1130, Singapore.

Address correspondence to: Dr. T.W.K. Lew, Department of Anaesthesia, Kandang Kerbau Hospital, 1 Hampshire Road, Singapore 0821, Singapore.

Accepted for publication 15th December, 1992
Thomas Wing Kit Lew MBBS MMed (Anaesthesia), Win Min San MBBS MMed (Anaesthesia) FFARACS, Mun Kui Chin MBBS BAO(NUI) FFARACS est modifié pour permettre linsufflation de quantités connues d'air ambiant grâce à un dispositif à trois voies intégré dans le circuit avec absorption et relié à un ventilateur à deux soufflets. Pendant la ventilation mécanique, des fuites de 50-150 $\mathrm{ml} \cdot \mathrm{min}^{-1}$ détectées et des nomogrammes calculant les quantités minimales d'air et d'oxygène requises pour maintenir une concentration constante d'oxygène compensant pour ces fuites sont colligés par méthode mathématique. L'exactitude de ces nomogrammes est vérifiée sur trois modèles différents d'appareil d'anesthésie à laide de modèles mécaniques de poumons. Aucune différence de concentration oxygénée n'est observée entre les trois appareils d'anesthésie. Les valeurs moyennes (SD) obtenues sont de $30,65 \%(0,77), 51,07 \%(1,04)$ et $70,4 \%(0,73)$ pour des concentrations inspirées prédites de 30,50 et $70 \%$ respectivement. La technique est appliquée par la suite à 18 patients anesthésiés à l'isoflurane ou au propofol (durée 40-210 min) pour des interventions variées. Les valeurs moyennes (SD) mesurées sont de 29,3\% (1,86), 40,95\% (1,65) et 50,06\% (1,41) respectivement pour des concentrations prédites de 30,40 et $50 \%$. Nous concluons que cette technique permet de délivrer avec précision des mélanges air-oxygène pendant l'anesthésie inhalatoire ou intraveineuse lorsque le $\mathrm{N}_{2} \mathrm{O}$ est contre-indiqué et qu'il n'y a pas de source d'air comprimé disponible.

The use of air-oxygen mixtures for ventilating the lungs of anaesthetized patients is desirable in operations where the volume effects of $\mathrm{N}_{2} \mathrm{O}$ are deleterious. Nitrous oxide has also been implicated with immunosuppression after prolonged exposure, increasing pulmonary vascular resistance, and myocardial depression in susceptible patients when administered together with opioid anaesthesia. 1,2 Despite renewed calls for avoiding the use of $\mathrm{N}_{2} \mathrm{O}$ in abdominal surgery, ${ }^{3-5}$ the place of $\mathrm{N}_{2} \mathrm{O}$ remains preeminent. One limitation may be the un-availability of a compressed air source in the operating theatre and a reluctance on the part of many anaesthetists to administer $100 \%$ oxygen for an extended period. Since the piped gas supply to many operating theatre suites does not include compressed air and many older anaesthetic machines do not have air flowmeters, current solutions include the use of compressed air cylinders to drive non- 
rebreathing ventilators or apparatus that entrain atmospheric air (e.g., East-Radcliffe ventilator, Tri-service apparatus).

An alternative solution considered in this paper is to maintain a constant reservoir of nitrogen in a closed circuit filled with an air-oxygen mixture. Since only oxygen is constantly consumed, it is possible to preserve a constant oxygen:nitrogen concentration ratio by continuous oxygen inflow sufficient to replace that taken up by the body. In practice, the most important problem is leakage of gas from the circuit during positive pressure ventilation. Dorsch recommended an acceptable combined leakage no greater than $100 \mathrm{ml} \cdot \mathrm{min}^{-1}$ for both the circle system and the anaesthetic machine at a pressure of $30 \mathrm{~cm} \mathrm{H}_{2} \mathrm{O}$ during pre-anaesthetic checking. ${ }^{6}$ The magnitude of the leak was found to be between $50-150 \mathrm{ml} \cdot \mathrm{min}^{-1}$ in our anaesthetic machines during intermittent positive pressure ventilation and resulted in the gradual depletion of gases from the circuit. If the oxygen inflow is increased to compensate for this leak, the inspired concentration of oxygen in the circuit will inevitably increase.

To overcome this problem, we interposed a three-way adapter between the common gas outlet and the fresh gas tube leading to the circle-absorber system. An adult manual resuscitator bag was then connected to the adapter (Figure 1) and this allowed for intermittent insufflation of atmospheric air into the circuit to re-inflate the ventilator bellows and dilute the oxygen concentration in the circuit. The intermittent addition of unquantified amounts of air into the circuit to replace leaked gas can be used to restore the circuit oxygen concentration to a desirable level using an in-circuit oxygen electrode as a guide. As gas mixing is not instantaneous, considerable fluctuations in circuit oxygen concentration may occur. This empirical approach is suitable only when delivery of anaesthesia is not dependent on the circuit, such as during total intravenous anaesthesia (TIVA), since small fluctuations in circuit oxygen concentration are unimportant as long as the patient does not receive high inspired concentrations of oxygen and is adequately oxygenated.

However, when the circuit is used for the delivery of inhalational anaesthesia, awareness may occur because an out-of-circuit vaporizer is favoured during mechanical ventilation with a closed circuit ${ }^{7}$ and anaesthetic vapour is thus delivered solely via the low oxygen fresh gas flow. Dilution of gases in the circuit due to insufflation of air on a trial and error basis leads to reductions in inspired anaesthetic concentration. This can be avoided by providing the minimal air and oxygen inflows required to maintain stable oxygen concentrations. We therefore attempted to determine these relative flowrates by analyzing the theoretical effect of leakage from a closed circuit on the inspired oxygen concentration. The result of

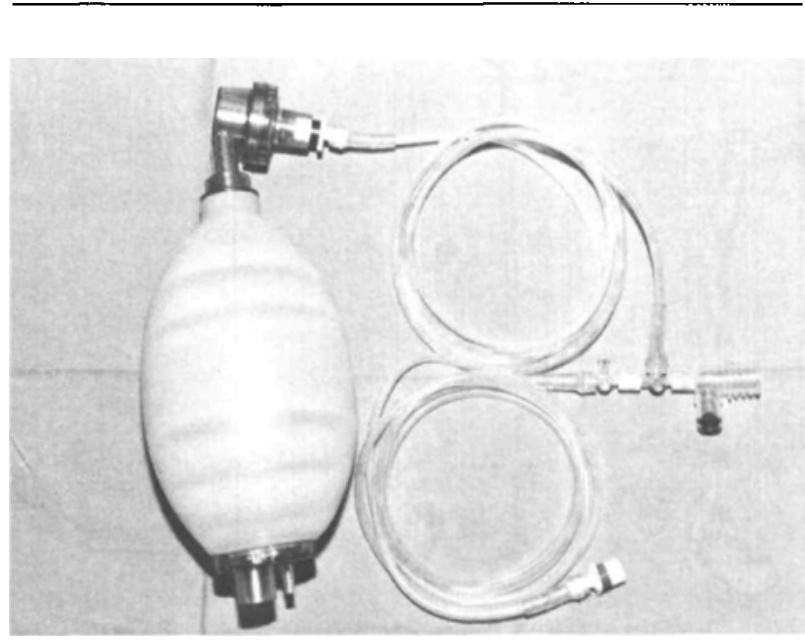

FIGURE I Tubing system connected by a three-way adapter for the insufflation of air into the circuit. One $15 \mathrm{~mm}$ Portex connector is attached to the common gas outlet (CGO) of the anaesthetic machine while the other is attached to the Laendal resuscitator. The $22 \mathrm{~mm}$ diameter end of a standard L-shaped gas sampling connector is attached to the common gas tubing that leads to the circuit. A second three-way tap is used to vent fresh gases from the CGO when air is being insufflated.

this analysis was then subjected to validation on test "lung" models and patients.

\section{Methods}

Analysis of leak from a closed system and its effects on inspired oxygen concentrations

The oxygen concentration of a closed anaesthetic system in which there is a constant inflow of oxygen and a simultaneous leakage of gases after unit time $\mathrm{dt}$ can be expressed as follows:

$\frac{V_{\mathrm{O}_{2}}+\mathrm{V}_{\mathrm{i}} \cdot \mathrm{dt}-\mathrm{av}\left(\mathrm{FO}_{2}\right) \cdot \mathrm{V}_{1} \cdot \mathrm{dt}}{\mathrm{V}_{\mathrm{c}}+\mathrm{V}_{\mathrm{i}} \cdot \mathrm{dt}-\mathrm{V}_{1} \cdot \mathrm{dt}}=\mathrm{f}\left(\mathrm{FO}_{2}\right)$

where:

$\mathrm{V}_{\mathrm{c}}$ : Volume of the circuit

$\mathrm{V}_{\mathrm{O}_{2}}$ : Initial volume of oxygen

$\mathrm{V}_{\mathrm{i}} \cdot \mathrm{dt}$ : Volume of oxygen inflow after unit time av $\left(\mathrm{FO}_{2}\right)$ : Average $\mathrm{O}_{2}$ concentration after unit time

$\mathrm{V}_{1} \cdot \mathrm{dt}$ : Volume of gas leaked after unit time, and $\mathrm{f}\left(\mathrm{FO}_{2}\right)$ : Final $\mathrm{O}_{2}$ fraction after unit time

Since the rate of change of oxygen concentration in the system is small, av $\left(\mathrm{FO}_{2}\right)$ can be substituted with the initial oxygen concentration in the system or $\left(\mathrm{FO}_{2}\right)$. This eliminates the need to measure the volume of the circuit in the subsequent calculations. Thus: 


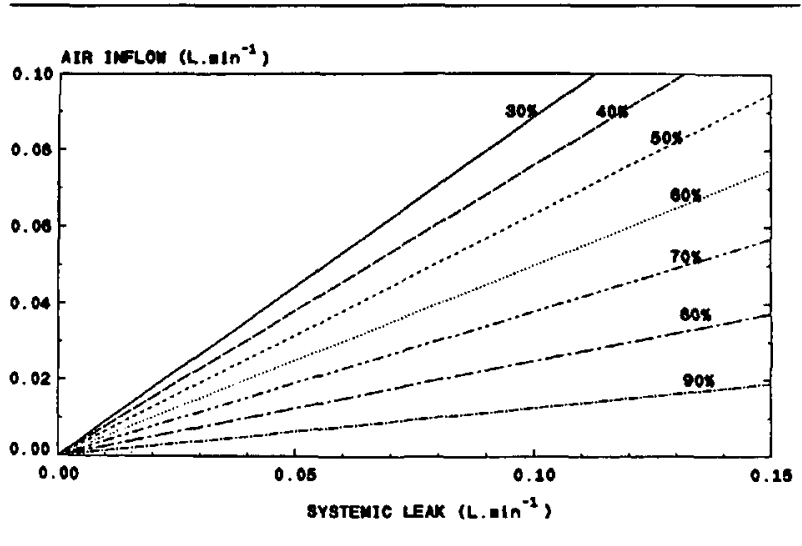

FIGURE 2 Nomogram showing air inflow rates against leakage rates from a closed circuit per unit time for different desired oxygen concentrations (30\%-90\%).

$\frac{\mathrm{V}_{\mathrm{O}_{2}}+\mathrm{V}_{1} \mathrm{dt}-\mathrm{i}\left(\mathrm{FO}_{2}\right) \cdot \mathrm{V}_{1} \cdot \mathrm{dt}}{\mathrm{V}_{\mathrm{c}}+\mathrm{V}_{\mathrm{i}} \cdot \mathrm{dt}-\mathrm{V}_{1} \cdot \mathrm{dt}}=\mathrm{f}\left(\mathrm{FO}_{2}\right)$

The net reduction $(\mathrm{R})$ in circuit volume after unit time is:

$\mathrm{R}=\mathrm{V}_{\mathrm{l}} \cdot \mathrm{dt}-\mathrm{V}_{\mathrm{i}} \cdot \mathrm{dt}$

If this volume loss is restored with the addition of atmospheric air with the aim of restoring the oxygen concentration of the system to its initial value, this can be expressed as:

$$
\begin{array}{r}
0.21\left(V_{1}-\left(V_{i}\right) \cdot d t+f\left(F O_{2}\right) \cdot\left(V_{c}+V_{i} d t-V_{1} \cdot d t\right)\right. \\
=i\left(F_{2}\right) \cdot V_{c}
\end{array}
$$

where $\mathrm{i}\left(\mathrm{FO}_{2}\right)$ is the initial oxygen concentration in the circuit.

Since $\mathrm{i}\left(\mathrm{FO}_{2}\right) \cdot \mathrm{V}_{\mathrm{c}}=\mathrm{V}_{\mathrm{O}_{2}}$ and substituting $\mathrm{f}\left(\mathrm{FO}_{2}\right)$ from equation (2) into (4) and simplifying,

$$
0.21\left(\mathrm{~V}_{\mathrm{l}}-\mathrm{V}_{\mathrm{i}}\right)+\mathrm{V}_{\mathrm{i}}=\mathrm{i}\left(\mathrm{FO}_{2}\right) \cdot \mathrm{V}_{1}
$$

or

$\mathrm{V}_{\mathrm{i}}=\left[\mathrm{i}\left(\mathrm{FO}_{2}\right)-0.21\right] \cdot \mathrm{V}_{1} / 0.79$

Where $V_{i}$ is the amount of oxygen inflow for a desired initial $\mathrm{O}_{2}$ concentration $\mathrm{i}\left(\mathrm{FO}_{2}\right)$ in the circuit with a known leakage $V_{1}$ per unit time.

Substituting (5) into (3), the amount of air $\mathrm{V}_{\mathrm{a}}$ needed to restore the circuit to its initial oxygen concentration after unit time $\mathrm{dt}$ is:

$\mathrm{V}_{\mathrm{a}}=\left[\mathrm{i}\left(\mathrm{FO}_{2}\right)-1\right] \cdot \mathrm{V}_{\mathrm{l}} / 0.79$

From equations (5) and (6), it can be seen that when the leakage rate of any given system is known, it is possible to determine the approximate minimal air and oxy-

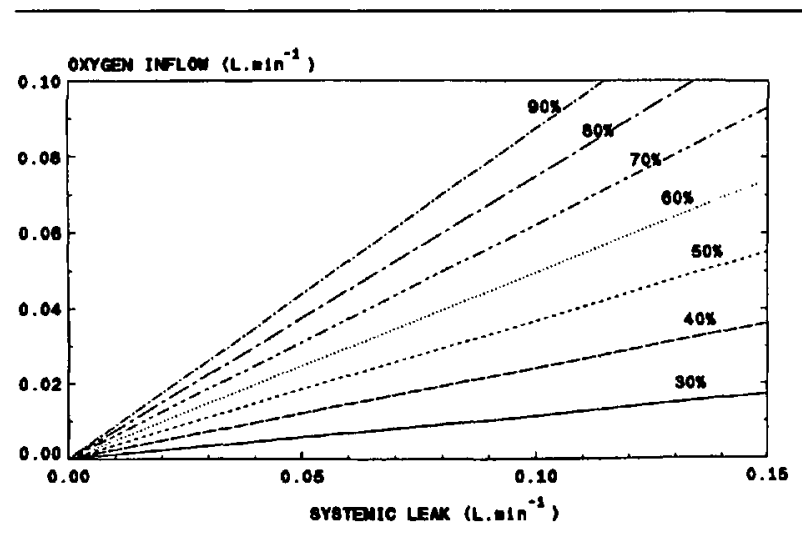

FIGURE 3 Nomogram showing oxygen inflow rates (greater than uptake) against leakage rates from a closed circuit per unit time for different desired oxygen concentrations $(30 \%-90 \%)$.

gen inflow rates into the system in order to maintain a desired oxygen concentration.

The nomograms from the derived equations (5) and (6) are shown in Figures 2 and 3 respectively.

\section{Validation of analysis}

\section{TEST MODELS}

In the test models, both air and oxygen inflow rates based on the nomograms were tested against known leakage rates in the circuits. As the Figure 3 nomogram for oxygen inflow rates does not take oxygen consumption into consideration, no device to stimulate oxygen uptake was necessary for the test model.

Three different anaesthetic machines (Blease Strata; Ohmeda International 2; Penlon AM700) and circle absorber circuits connected to test "lung" bags were tested. An Airshields Ventimeter II double circuit ventilator with a $1.5 \mathrm{~L}$ spirometric collapsible bellows was used. The test circuit is shown in Figure 4. Oxygen concentrations were monitored by an Albion Raman scattering gas analyzer (RASCAL). Analyzed gases were returned into the circuit.

Initially, the leakage rate of the system was determined by observing the rate of fall of the bellows during ventilation of the test "lung" bag with no fresh oxygen flow at empirical settings of a peak airway pressure of $20 \mathrm{~cm}$ $\mathrm{H}_{2} \mathrm{O}$, I:E ratio of $1: 4$ and rate of $12 \cdot \mathrm{min}^{-1}$. Subsequently, the amounts of fresh oxygen and air inflow rates for the obtained leakage rate was read from the nomograms for a desired oxygen concentration of $30 \%$. The circuit was then primed with $30 \%$ oxygen. The test "lung" was then ventilated with the predetermined oxygen inflow (obtained from Figure 1) over ten minutes. Ventilation was then stopped and the volume of air derived from Figure 


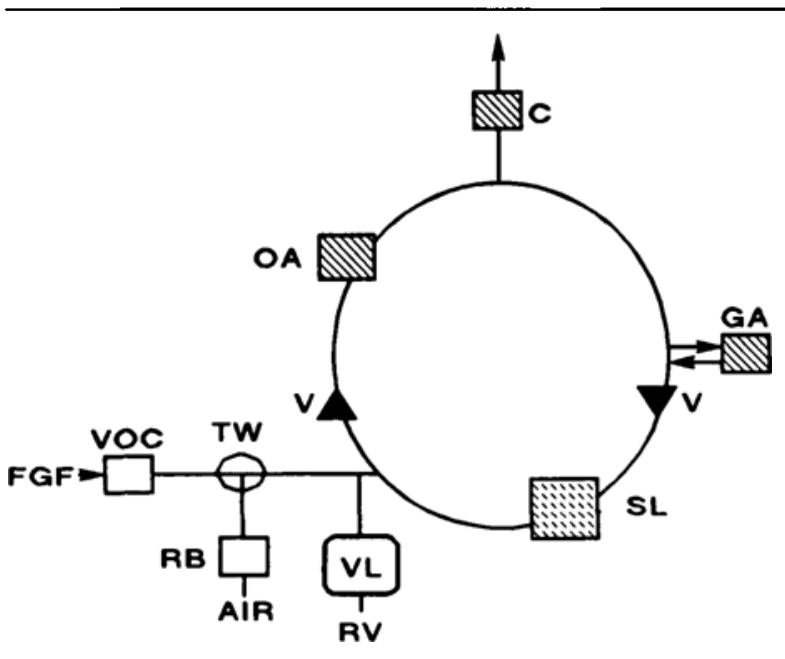

FIGURE 4 Components of the closed system used. $\mathrm{C}=\mathrm{CO}_{2}$ analyzer or RASCAL gas analyzer, $\mathrm{GA}=$ anaesthetic gas analyzer, $\mathrm{V}$ $=$ unidirectional valves, $\mathrm{SL}=\mathrm{CO}_{2}$ sodalime absorber, $\mathrm{VL}=$ Airshields ventilator, $\mathrm{RB}=$ resuscitator bag, $\mathrm{AIR}=$ air inflow, $\mathrm{TA}=$ three-way attachment, $\mathrm{VOC}=$ vaporizer (out-of-circuit), $\mathrm{FGF}=$ oxygen inflow, $\mathrm{OA}=$ oxygen analyzer, $\mathrm{RV}=$ low-pressure release valve (not utilized during closed circuit anaesthesia).

2 was insufflated into the system, restoring the bellows to its original volume. Ventilation was then resumed. This cycle was repeated for a total of $60 \mathrm{~min}$. This cycle was repeated for a total of $60 \mathrm{~min}$. This procedure was repeated twice on each anaesthetic machine for oxygen concentrations of $50 \%$ and $70 \%$. The peak and trough oxygen concentrations during each ten-minute interval before and after insufflation of air were recorded.

\section{PATIENTS}

In the clinical study, the leakage rate of the machines used were initially tested on a test lung bag. The quantity of air to be insufflated at regular intervals during anaesthesia was then determined from the nomogram in Figure 2 for the desired oxygen concentration. This was equivalent to the net volume of gas to be leaked from the circuit during the same intervals. The difference in the greater volume leaked at zero gas flows (on the test lung) and this net volume to be leaked during anaesthesia was made up for by the oxygen inflow. Since the nomogram for oxygen inflow rates (Figure 3) does not take into account oxygen consumption of individual patients, it was not used. Oxygen inflow was instead titrated to allow the net volume to be leaked from the circuit at regular intervals.

After obtaining informed consent and institutional approval for the study, 18 patients were studied using this technique. The patients were divided into three groups and their lungs were ventilated with oxygen concentra- tions of 30,40 and $50 \%$. The monitoring devices used in the circuit were a Critikon Oxycheck oxygen electrode in the inspiratory limb, a Siemens Servo Gas Monitor 120 in the expiratory limb and a Siemens in-circuit endtidal $\mathrm{CO}_{2}$ analyzer at the patient end of the circuit. Analyzed gases were returned into the circuit.

The patients initially breathed spontaneously for five minutes via a mask connected to a Laerdal resuscitator enriched with oxygen at a flowrate based on the manufacturer's performance data to deliver approximately the intended intraoperative oxygen concentration.

After induction of anaesthesia and paralysis, the lungs were manually ventilated using the Laerdal resuscitator for a further minute before tracheal intubation. The cuffed endotracheal tube was then connected to the anaesthetic circuit which had been previously primed with ambient air ( $21 \%$ oxygen). The lungs were then ventilated (to maintain an approximate end-tidal $\mathrm{CO}_{2}$ concentration of $5 \mathrm{kPa}$ ) and oxygen inflows of 0.5 to $1 \mathrm{~L} \cdot \mathrm{min}^{-1}$ were started to allow the inspired oxygen concentration to rise to the desired eoncentration. The oxygen inflow was then adjusted to allow the bellows to leak to the predetermined volume loss after a period of ten minutes. Ambient air was then insufflated to restore the bellows to its original position and the cycle repeated. In patients receiving isoflurane/opioid anaesthesia, an Ohmeda Tec 4 out-ofcircuit vaporizer was initially set at $5 \%$ and the settings titrated according to the gas monitor to achieve an expired steady state isoflurane concentration of between $0.8-1 \%$. The patients were randomly assigned for ventilation with oxygen concentrations of $40 \%$ or $50 \%$. Patients receiving propofol and opioid anaesthesia empirically received ventilation with an oxygen concentration of $30 \%$. The peak and trough oxygen concentrations were measured in all groups at ten-minute interval.

\section{Results}

\section{Test models}

The regression lines joining the mean oxygen concentrations obtained from each anaesthetic machine at tenminute intervals after one hour of ventilation are plotted in Figure 5. There were no differences between the mean oxygen concentrations observed using the three anaesthetic machines. ( $P=\mathrm{NS}$, ANOVA). Thus the use of different machines with different circuit volumes did not affect the performance of the technique. The pooled mean values (SD) obtained from the three machines were $30.65 \%(0.77), 51.07 \%(1.04)$ and $70.45 \%(0.73)$ for predicted inspired oxygen concentrations of 30,50 and $70 \%$ respectively based on the nomogram values derived from the mathematical analysis. These values were consistently greater than the predicted oxygen concentrations in the 


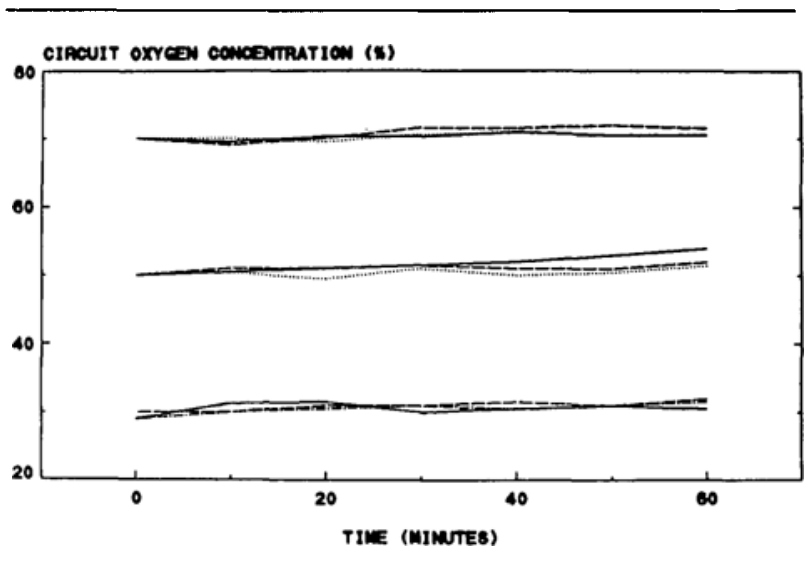

FIGURE 5 Oxygen concentrations obtained over $60 \mathrm{~min}$ in three anaesthetic machines based on predicted values of 30,50 and $70 \%$. Pooled mean concentrations (SD) were $30.65 \%(0.77), 51.07 \%(1.04)$ and $70.45 \%(0.73)$ respectively. (Legend: Ohmeda International $2=$ -- , Penlon AM $700=\ldots$, Blease Strata $=\ldots . . . .$.$) .$

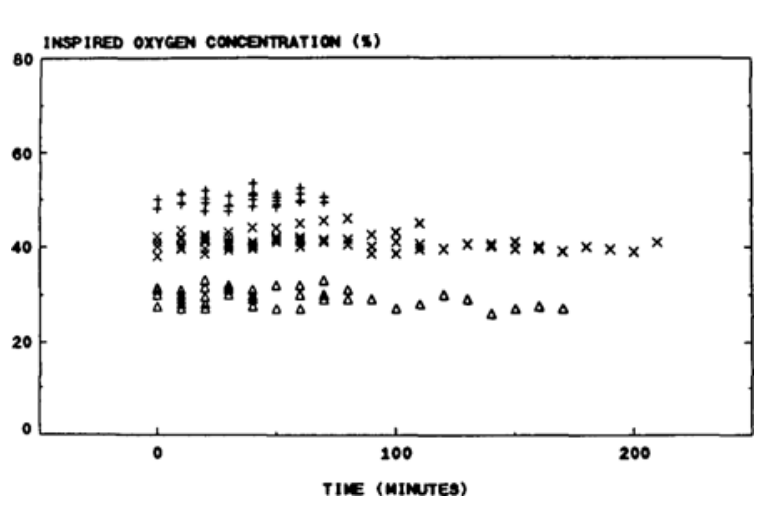

FIGURE 6 Inspired oxygen concentrations measured at ten-minute intervals against time in 18 patients who underwent isoflurane/opioid or propofol/opioid anaesthesia ranging from $40-210 \mathrm{~min}$. Not all 142 readings measured can be seen because of some overlap of similar values. (Legend: $\Delta=30 \%, X=40 \%,+=50 \%$ oxygen concentration).

system as they reflected the means of the greatest and lowest oxygen concentrations measured before and after re-insufflation with ambient air.

\section{Patients}

Of the 18 patients studied, seven received isoflurane/ opioid anaesthesia with $40 \%$ oxygen, six received isoflurane/opioid anaesthesia with 50\% oxygen and five received propofol/opioid with 30\% oxygen. The patients' profiles and types of surgery performed are shown in the Table. Figure 6 shows the mean oxygen concentrations plotted every ten minutes in the three groups of patients. The pooled mean values (SD) obtained were
TABLE Patient and procedure characteristics (mean (SD))

\begin{tabular}{llll}
\hline Groups & $30 \% \mathrm{O}_{2}$ & $40 \% \mathrm{O}_{2}$ & $50 \% \mathrm{O}_{2}$ \\
$n$ & 5 & 7 & 6 \\
Age (yr) & $31.2(12.4)$ & $37.4(15.6)$ & $34.3(14.9)$ \\
Duration of anaesthesia (min) & $101(59)$ & $84(45)$ & $60(8)$ \\
Tympanoplasty & 1 & & 2 \\
$\begin{array}{l}\text { Mastectomy } \\
\text { Fixation talus fracture }\end{array}$ & 1 & 1 \\
$\begin{array}{l}\text { Thyroidectomy } \\
\text { Hemicolectomy/adhesiolysis }\end{array}$ & 1 & \\
$\begin{array}{l}\text { Cholecystectomy/CBD } \\
\text { exploration }\end{array}$ & 1 & 1 \\
$\begin{array}{l}\text { Superficial parotidectomy } \\
\text { Mastoidectomy }\end{array}$ & 1 & 1 & \\
Repair abdominal incisional & & 1 & \\
$\quad$ hernia & & & \\
$\begin{array}{l}\text { Elevation parietal bone fracture } \\
\text { Intra-nasal antrostomy }\end{array}$ & 1 & & \\
Nasal septoplasty & 1 & & \\
Arthroscopic meniscectomy & & 1 & \\
\hline
\end{tabular}

$29.3 \%(1.86), 40.95 \%(1.65)$ and $50.06 \%(1.41)$ for predicted concentrations of 30,40 and $50 \%$ respectively. Small differences between the leakage rate predicted from a test "lung" bag and the patient were observed due to variations in chest compliance and small leaks from the endotracheal cuffs.

However, once the leakage rates were adjusted appropriately and the patients' oxygen consumptions reached steady states, no further variations in the leakages and volumes of air re-insufflated were observed. Although not measured specifically, it was observed that isoflurane concentrations using the Tec 4 vaporizer took an average of five to seven minutes to achieve a stable expired concentration of $0.8-1.0 \%$. The shorter durations were achieved in the group ventilated with 50\% oxygen since more isoflurane was delivered initially with greater oxygen inflow rates maintained for longer durations at induction. Insufflation of air at ten-minute intervals resulted in variation of expired isoflurane concentration no greater than $0.1 \%$. The constancy of the alveolar isoflurane concentrations was thus maintained within reasonable limits.

\section{Discussion}

In this study, we have described a simple modification to an anaesthetic machine to enable delivery of airoxygen mixtures via a closed circuit during positive pressure ventilation where oxygen is the sole compressed gas source available. By providing minimal air and oxygen inflows based on a predetermined nomogram to replace leaked gases, it was further shown that constant gas mixtures of varying oxygen concentrations could be delivered during isoflurane and total intravenous anaesthesia. 
Although the mathematical analysis used to derive this technique focused on exploiting the effects of leakage, other factors affecting the stability of the system were also considered; the effects of nitrogen wash-in into the closed circuit, intraoperative variations in oxygen consumption of the patients and deviation from the predetermined leakage rates of the circuit. The effects of nitrogen wash-out are known to alter considerably the composition of gases in a closed circuit with time unless the circuit is vented periodically. Approximately $60 \%$ of body nitrogen, or $1.6 \mathrm{~L}$, resides in the functional residual capacity of a $60 \mathrm{~kg}$ man and is rapidly exchangeable. In this study, washout from this reservoir was minimised by pre-ventilating the lungs with an oxygen concentration close to that desired intraoperatively. This reduced the differences in nitrogen concentrations between the patients' functional residual capacities and the circuits. Release of the remaining nitrogen from the body compartments occurs slowly and was estimated by Barton and $\mathrm{Nunn}^{8}$ to contribute an average of $10 \mathrm{vol} \%$ to the closed circuit per hour of $\mathrm{O}_{2}: \mathrm{N}_{2} \mathrm{O}$ anaesthesia. This figure is likely to be much smaller in our study because of the small gradient that exists between body and circuit nitrogen concentration (78\% to $50-70 \%$ ) and the absence of a more soluble gas such as nitrous oxide to displace body nitrogen. Although our patients exhibited fairly constant oxygen consumption during anaesthesia, variation in oxygen consumption during anaesthesia can occur but will not affect the performance of the technique insofar as the oxygen inflow is adjusted accordingly to maintain the same leakage rate initially determined before induction of anaesthesia. However, the stability of the gas mixtures will be affected if large variations or deviations from the predetermined leakage rate occur due to patient factors, e.g., changes in lung compliance or disconnections of the endotracheal tube from the circuit. As stated earlier, such changes are only important insofar as the circuit is used to deliver a volatile anaesthetic. Anaesthesia for such patients may instead by maintained with intravenous agents and the inspired oxygen concentrations delivered allow to vary within a broader range.

Despite the above limitation, this technique compares favourably with non-rebreathing systems of delivering volatile anaesthetics in air-oxygen mixtures. It causes less atmospheric pollution, reduces the use of volatile anaesthetics and does not require additional monitoring devices not currently in clinical use. It should be remembered, however, that an in-circuit anaesthetic gas monitor is mandatory if volatile anaesthetics are used since the settings in an out-of-circuit vaporizer does not reflect incircuit concentrations.

The ability to deliver stable air-oxygen mixtures during anaesthesia when $\mathrm{N}_{2} \mathrm{O}$ is undesirable reduces the possible complications associated with the use of pure oxygen. The usefulness of this technique depends on the availability of alternative sources of compressed air. As operating room suites and anaesthetic machines are modernized, this deficit will be rectified and its usefulness will diminish accordingly.

\section{References}

1 Stoelting RK, Gibbs P'S, Creasser CW, Peterson C. Hemodynamic and ventilatory responses to fentanyl, fentanyl-droperidol, and nitrous oxide in patients with acquired valvular heart disease. Anesthesiology 1975; 42 : 319-24.

2 Stoelting RK, Gibbs PS. Hemodynamic effects of morphine and morphine-nitrous oxide in valvular heart disease and coronary-artery disease. Anesthesiology 1973; 38: 45-52.

3 Scheinin B, Lindgren L, Scheinin TM. Peroperative nitrous oxide delays bowel function after colonic surgery. $\mathrm{Br}$ J Anaesth 1990; 64: 154-8.

4 Thomas DV. Nitrous oxide should not be used during laparoscopy nor during other abdominal operations (Correspondence). Anaesthesia 1992; 47: 80-1.

5 Veheecke $G$. Nitrous oxide and laparoscopy (Correspondence). Anaesthesia 1991: 46: 698.

6 Dorsch JA, Dorsch SE. Understanding Anesthesia Equipment: Construction, Care and Complications. 2nd Ed. Baltimore. Williams \& Wilkins, 1984; 403-5.

7 White $D C$. Vaporization and vaporizers. $\mathrm{Br} \mathrm{J}$ Anaesth 1985; 57: 658-71.

8 Barton F, Nunn JF. Totally closed circuit nitrous oxide/ oxygen anaesthesia. Br J Anaesth 1975; 47: 350-7. 